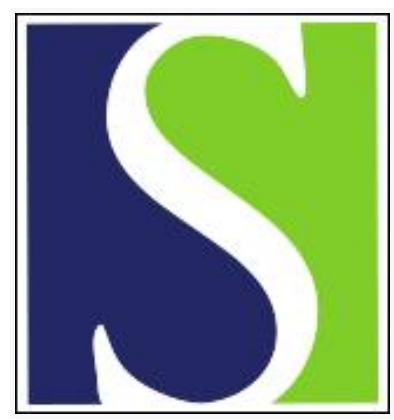

Scand J Work Environ Health 2013;39(5):495-505

https://doi.org/10.5271/sjweh.3351

Published online: 19 Feb 2013, Issue date: 01 Sep 2013

Prevalence and incidence of carpal tunnel syndrome in US working populations: pooled analysis of six prospective studies

by Dale AM, Harris-Adamson C, Rempel D, Gerr F, Hegmann K, Silverstein B, Burt S, Garg A, Kapellusch J, Merlino L, Thiese MS, Eisen EA, Evanoff $B$

Few studies have adequate power to explore causal relationships for carpal tunnel syndrome. This paper describes the pooling of data across six prospective CTS studies and reports 204 cases of CTS from 3515 workers in the incidence analysis. This data provides adequate power for future exposure-response analyses to identify work and non-work related risk factors for CTS.

Affiliation: Washington University School of Medicine, 660 South Euclid Avenue, Campus Box 8005, St Louis, MO, 63110, USA. adale@dom.wustl.edu

Refers to the following texts of the Journal: 2013;39(2):155-163

2011;37(4):298-306 2010;36(5):384-393 2009;35(1):19-36 1998;24(4):285-292 1997;23(5):364-369

The following articles refer to this text: 2014;40(1):100; 2014;40(1):101-102; 2014;40(6):610-620; 2017;43(1):75-85; 2018;44(6):555-556

Key terms: carpal tunnel syndrome; CTS; epidemiology; incidence; industry; longitudinal study; median nerve; MSD; musculoskeletal disorder; nerve compression; occupational injury; prevalence; prospective study; surveillance; USA; work-related injury

This article in PubMed: www.ncbi.nlm.nih.gov/pubmed/23423472

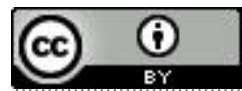




\title{
Prevalence and incidence of carpal tunnel syndrome in US working populations: pooled analysis of six prospective studies
}

\author{
by Ann Marie Dale, PhD, ${ }^{1}$ Carisa Harris-Adamson, PhD, ${ }^{2}$ David Rempel, MD, ${ }^{3}$ Fred Gerr, MD, ${ }^{4}$ Kurt \\ Hegmann, MD, ${ }^{5}$ Barbara Silverstein, PhD, ${ }^{6}$ Susan Burt, ScD, ${ }^{7}$ Arun Garg, PhD, ${ }^{8}$ Jay Kapellusch, PhD, ${ }^{8}$ \\ Linda Merlino, MS, ${ }^{4}$ Matthew S Thiese, PhD, ${ }^{5}$ Ellen A Eisen, PhD, ${ }^{9}$ Bradley Evanoff, MD ${ }^{1}$
}

Dale AM, Harris-Adamson C, Rempel D, Gerr F, Hegmann K, Silverstein B, Burt S, Gang A, Kapellusch J, Merlino L, Thiese MS, Eisen EA, Evanoff B. Prevalence and incidence of carpal tunnel syndrome in US working populations: pooled analysis of six prospective studies. Scand J Work Environ Health. 2013;39(5):495-505. doi:10.5271/sjweh.3351

\begin{abstract}
Objectives Most studies of carpal tunnel syndrome (CTS) incidence and prevalence among workers have been limited by small sample sizes or restricted to a small subset of jobs. We established a common CTS case definition and then pooled CTS prevalence and incidence data across six prospective studies of musculoskeletal outcomes to measure CTS frequency and allow better studies of etiology.

Methods Six research groups collected prospective data at $>50$ workplaces including symptoms characteristic of CTS and electrodiagnostic studies (EDS) of the median and ulnar nerves across the dominant wrist. While study designs and the timing of data collection varied across groups, we were able to create a common CTS case definition incorporating both symptoms and EDS results from data that were collected in all studies.

Results At the time of enrollment, $7.8 \%$ of 4321 subjects met our case definition and were considered prevalent cases of CTS. During 8833 person-years of follow-up, an additional 204 subjects met the CTS case definition for an overall incidence rate of 2.3 CTS cases per 100 person-years.

Conclusions Both prevalent and incident CTS were common in data pooled across multiple studies and sites. The large number of incident cases in this prospective study provides adequate power for future exposureresponse analyses to identify work- and non-work-related risk factors for CTS. The prospective nature allows determination of the temporal relations necessary for causal inference.
\end{abstract}

Key terms CTS; epidemiology; industry; longitudinal study; median nerve; MSD; musculoskeletal disorder; nerve compression; occupational injury; surveillance; work-related injury.

Carpal tunnel syndrome (CTS) is the most expensive upper-extremity musculoskeletal disorder (UEMSD) at an estimated cost of medical care in the US exceeding \$2 billion annually, primarily due to surgical releases (1). The non-medical costs are substantially greater. In the US, the median lost worktime from work-related CTS is 27 days, which is longer than any other work-related disorder except fractures $(2,3)$. Furthermore, $18 \%$ of workers who develop CTS reported leaving their job within 18 months
(4). Although CTS is a strong driver of workers' compensation costs, lost wages, lost productivity, and disability $(1,2)$, there is still an incomplete understanding of its frequency and causes in working populations.

Estimates of CTS prevalence and incidence vary widely in the literature. The prevalence of electrophysiologically confirmed CTS in working populations is generally higher than in the general population. Prevalent CTS among manufacturing and meat-packing workers

1 Division of General Medical Science, Washington University School of Medicine, Saint Louis, MO, USA.

2 Department of Physical Therapy, Samuel Merritt University, Oakland, CA, USA.

3 Division of Occupational and Environmental Medicine, University of California at San Francisco, San Francisco, CA, USA.

4 University of Iowa, Department of Occupational and Environmental Health, College of Public Health, Iowa City, IA, USA.Rocky Mountain Center for Occupational and Environmental Health (RMCOEH), University of Utah, Salt Lake City, UT, USA.

5 Safety \& Health Assessment and Research for Prevention (SHARP) Program, Washington State Department of Labor \& Industries, Olympia, WA, USA.

6 National Institute for Occupational Safety and Health (NIOSH), Cincinnati, OH, USA.

7 Center for Ergonomics, University of Wisconsin-Milwaukee, Milwaukee, WI, USA.

8 University of California Berkeley, UC Berkeley School of Public Health, Berkeley, CA, USA.

Correspondence to: Ann Marie Dale, Washington University School of Medicine, 660 South Euclid Avenue, Campus Box 8005, St Louis, MO, 63110, USA. [E-mail:adale@dom.wustl.edu] 
has ranged from $5-21 \%(5-8)$ while prevalence proportions in general populations range from $1-5 \%(9-12)$. The data source, study design, and CTS case definition may have large effects on the measured prevalence proportions. Incidence rates of CTS calculated from Washington State workers' compensation records ranged from $0.8-14.8$ per 1000 person-years and varied by industrial and occupational classifications (13). Similar rates of 12.4 per 1000 person-years were observed among 432 industrial and clerical workers using a case definition requiring electrodiagnostic confirmation (14).

Relatively few prospective studies have examined the relationships between work and non-work factors and new cases of incident CTS. To our knowledge there is only one large prospective study that has done so Bonfiglioli and colleagues (15) studied a population of 4097 workers assessed prospectively for CTS and found a dose-response relationship between the American Conference of Governmental Industrial Hygienists threshold limit values (ACGIH TLV) classification and risk for CTS. While growing evidence suggests that work activities are associated with CTS, most studies have been limited by retrospective or cross-sectional design, non-specific case definitions, or imprecise exposure assessment (16-17). Such limitations in past studies have led some authors to state that workplace factors pose an "uncertain relationship to CTS" (18) while other studies have concluded that up to $50 \%$ of CTS cases are caused by work and could be prevented (19). Such causal uncertainty has likely delayed prevention efforts.

The relatively low incidence rates of CTS and the difficulties experienced when quantifying workplace exposures has made investigations of CTS causation quite challenging. Many large epidemiologic studies of electrodiagnostically confirmed CTS have estimated occupational exposure to physical risk factors with imprecise methods such as job titles or self-reported exposures (11, 20-21). Conversely, studies using detailed observational or direct methods for quantifying workplace exposures have been limited to smaller samples or single occupations $(14-15,22-25)$. While meta-analyses and systematic reviews can combine or compare studies of similar design, differences in design detail may limit their validity (26). By contrast, pooling data across studies can provide larger sample sizes and allow for direct examination of the comparability of data sources and methods.

In 2000, the US National Institute for Occupational Safety and Health (NIOSH) announced the availability of funding for prospective studies to evaluate the relationship between workplace factors and UEMSD, including CTS. Seven NIOSH-funded research groups formed the UEMSD Consortium to collaborate on studies of physical exposures and UE health outcomes, as well as to improve the potential for data pooling. All studies were prospective in design and collected symptom information, physical examination findings, and electrodiagnostic study (EDS) results to ascertain prevalent and incident MSD outcomes. In addition, all studies collected detailed workplace physical exposure data on all subjects.

In 2009, the UEMSD consortium received funding from NIOSH to pool data from six of the seven studies. Methods used to pool workplace physical exposure data have been described elsewhere in a manuscript by Kapellusch and colleagues, authors from the UE MSD consortium (27). The objectives of the present paper are to (i) describe the data available for establishing a common CTS case definition from six of the original consortium groups, (ii) describe the comparability of data elements across studies, and (iii) present the CTS prevalence and incidence rates for each study group and for the pooled cohort. This is the first in a series of papers describing CTS in this large, multi-center, prospective cohort study of workplace exposures and CTS.

\section{Methods}

\section{Study population}

Subjects in all studies were fulltime male and female employees aged $\geq 18$ years, who were employed in settings where some or all workers performed handintensive activities. Subjects were recruited primarily from industries representing manufacturing, production, service, construction, and healthcare. Approximately $18 \%$ of the workers performed jobs of lower hand intensity, including clerical and technical workers. In total, workers were recruited from $>50$ employers or building trade unions across the six study groups. Data collection began in 2001 and ended in 2010. The respective institutional review boards approved the studies and written informed consent was obtained from all participants.

\section{Study design}

All study groups administered baseline questionnaires on demographics, medical history, psychosocial factors, work history, and musculoskeletal symptoms. The duration of each study ranged from 2-7 years. Symptom information was collected at regular intervals in all studies, though the length of intervals varied between one week and one year between studies (figure 1). The number of follow-up symptom assessments collected from each subject ranged from 3-147 depending upon the frequency of questionnaires and duration of each follow-up. In five groups, EDS of the median and ulnar nerves of the wrist were collected along with UE physical examinations for all subjects at baseline. The sixth study group (Study D) performed baseline EDS only on those subjects who 
reported symptoms characteristic of CTS. Three studies (Studies A, E, F) performed bilateral EDS while the other studies performed unilateral EDS of the dominant hand. Follow-up EDS were administered at predefined periodic intervals in five studies (Studies A, B, D, E, F). Two of these studies also performed EDS following report of new hand symptoms (Studies C \& E). The sixth study (D) only performed follow-up EDS among subjects with new hand symptoms. In all study groups, outcome assessors were blinded to the exposure status of the subjects.

\section{CTS hand symptom definition}

Hand symptoms and onset date were assessed using surveys or interviews at frequencies ranging from weekly to annually. For three studies (A, B, F), subjects who reported positive symptoms by survey were asked to fill out a hand symptom diagram to show the location of symptoms and describe the type of symptoms experienced in the hand. Hand diagrams were coded following a standard or modified Katz scoring system $(28,29)$, which have shown excellent inter-rater and intra-rater reliability and validity in methodological studies performed by two of the study groups $(30,31)$. For studies using hand diagrams, the CTS hand symptom case definition for the pooled study required subjects to report characteristic symptoms in $\geq 1$ median innervated digit (ie, a hand diagram consistent with classic, probable, or possible CTS). The remaining three studies (C, D, E) interviewed all subjects who reported recent hand symptoms in order to determine the location and type of symptoms. The CTS hand symptoms case definition required that subjects report symptoms of tingling, numbness, burning, or pain in $\geq 1$ of the first three digits (thumb, index finger, or long finger) (table 1).

\section{Electrodiagnostic procedures}

All studies collected median nerve motor and sensory and ulnar nerve sensory conduction latencies across the wrist (table 2). Four study groups used conventional electrophysiology/electromyography equipment (XLTEC Neuromax 1002, Cadwell, Oxford Synergy, Teca Sapphire2P) and two studies used a portable nerve testing device (NC-stat, Neurometrix Inc, Waltham, MA, USA). A previous comparison of measures made with conventional equipment and the $\mathrm{NC}$-stat devices showed good correlation of median motor and sensory nerve conduction latencies between measures (32). All study groups followed recommended electrodiagnostic testing protocols (10).
A

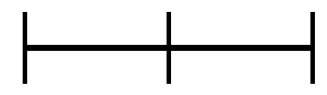

Annual symptoms and EDS for all

B

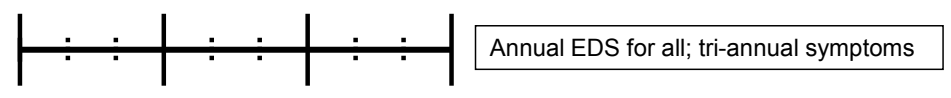

C

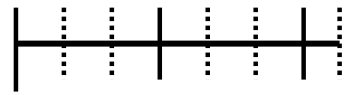

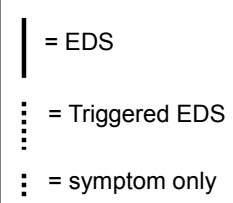

EDS $=$ electrodiagnostic

studies

D

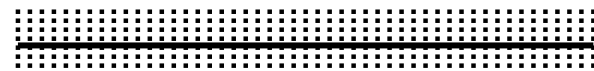
Weekly symptoms triggered EDS

E

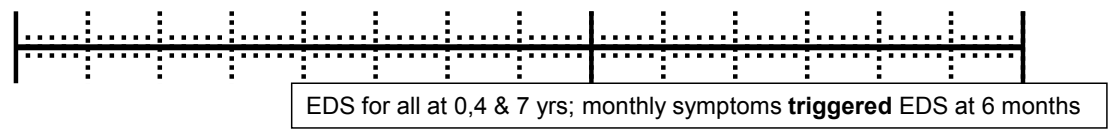

$\mathbf{F}$
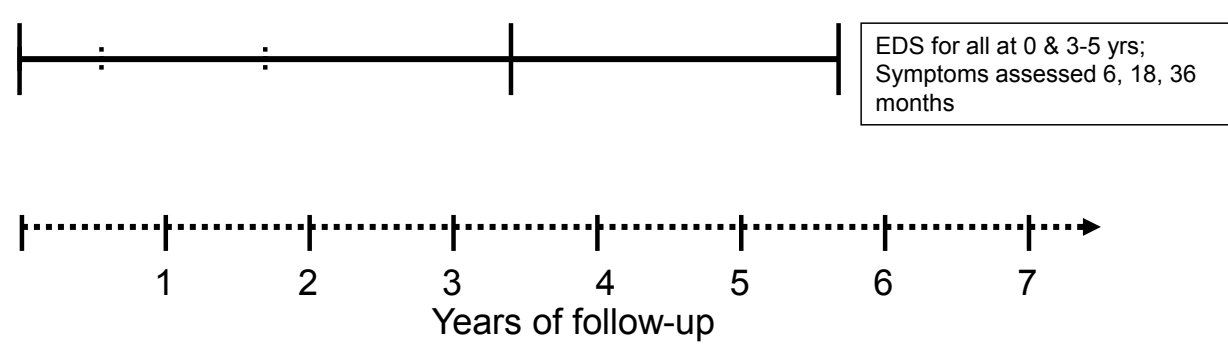

Figure 1. Data collection and study design for six original studies (A-F). NCS=nerve conduction study. 


\section{Electrode distance measures}

Procedures for recording the conduction distance between the stimulus and response electrode allowed standardizing of latency values. Two studies (A \& B) used predetermined distances between stimulating and recording electrodes for sensory $(14 \mathrm{~cm})$ and motor $(8$ $\mathrm{cm}$ ) latency measurement. The remaining studies placed electrodes with reference to anatomical landmarks and recorded distances between them. The sensory latency values were adjusted to a standard distance of $14 \mathrm{~cm}$ using the following equation: corrected sensory latency $=[($ measured sensory latency $/$ measured distance $) \times 14$ $\mathrm{cm}]$. In a similar way, the motor latency values were adjusted to a standard distance of $8 \mathrm{~cm}$ using the following equation: corrected motor latency $=[$ (measured motor latency $/$ measured distance $) \times 8 \mathrm{~cm}]$. The $\mathrm{NC}$-stat device uses a volume conduction methodology for measuring motor latency so length adjustments were not applied to these median motor latency values $(31,33)$.

\section{Temperature and waveform corrections}

All studies measured and recorded skin temperature prior to testing. The location of temperature measurement differed between studies: two studies measured temperature at the palm, two at the volar wrist, and two on the dorsum of the hand. Five of six study groups used warming procedures to reach a minimum specified skin temperature $\left(30-32^{\circ} \mathrm{C}\right)$. To correct latency values for differences in recorded temperatures, regression analyses were conducted to estimate the change in latency per degree change in temperature. Analyses were performed separately for each study using data from all asymptomatic subjects whose values fell within three standard deviations of the mean latency for that study group. Nerve conduction latency values were corrected to $32^{\circ} \mathrm{C}$ by using the betas derived from the regression equations and applied to data from the corresponding study. Corrections for nerve conduction latencies across studies ranged from $0-0.10 \mathrm{~ms}$ per degree $<32{ }^{\circ} \mathrm{C}$.

Sensory latency values were measured from stimulation artifact to the onset of the sensory nerve action potential by one study, while the remainder measured sensory latency to peak of the sensory nerve action potential. A correction of $0.5 \mathrm{~ms}$ was added to the onset sensory latency so values were comparable to the peak sensory nerve values. Since all of the motor latencies were recorded to the onset of the compound motor action potential, no adjustments were made. Temperature and electrode distance-adjusted median motor and median sensory and ulnar sensory nerve conduction latencies were used for electrophysiological confirmation of CTS.

\section{CTS case definition}

The CTS case definition used in the pooled study analysis required both CTS hand symptoms and EDS results consistent with median nerve mononeuropathy at the wrist (34). A pooled dataset, including hand symptoms and EDS values was assembled from results obtained by each study. The adjustments to EDS results were made prior to the creation of the pooled dataset. Cut-off points for defining nerve conduction abnormalities consistent with median mononeuropathy at the wrist were based on review of the relevant literature and analyses within consortium studies $(15,35-38)$. Specifically, the electrophysiological case definition of median mononeuropathy of the wrist used for the pooled analysis of the dominant hand was: (i) peak median sensory latency $>3.7 \mathrm{~ms}$ (at $14 \mathrm{~cm}$ ) or absent response or (ii) median motor latency $>4.5 \mathrm{~ms}$ or (iii) paired transcarpal median-ulnar sensory delta of $>0.85 \mathrm{~ms}(14 \mathrm{~cm})$ (defined as the difference in sensory latency of the median to the ulnar nerve). Unobtainable latency results that were due to nerve pathology (extremely prolonged latencies or very small amplitudes) also met the criteria for abnormal EDS in the case definition.

\section{Polyneuropathy of the upper extremity}

To distinguish subjects with polyneuropathy from those with CTS, we identified subjects with ulnar sensory nerve peak latencies of $\geq 3.68 \mathrm{~ms}$. This value corresponds to an ulnar sensory nerve conduction velocity of $44 \mathrm{~m} / \mathrm{s}$, a commonly used lower bound of normal ulnar sensory nerve conduction velocity (38). Subjects with abnormal ulnar sensory latencies who also met the CTS case definition were excluded from the CTS case count and censored at that time.

\section{Prevalence analysis}

Subjects meeting electrophysiological criteria for polyneuropathy at baseline were eliminated from further analysis $(\mathrm{N}=58)$. Subjects who met the pooled CTS study case definition for the dominant hand or reported prior carpal tunnel release (CTR) surgery at the time of entry into study were identified as prevalent CTS cases. The number and proportion of prevalent cases are reported for both the pooled cohort and separately for each study.

\section{Incidence analysis}

The incidence analysis included all subjects at risk of becoming a new CTS case during follow-up. Each subject contributed person time to the CTS incidence analysis until he/she (i) completed the study, (ii) was lost to follow-up (dropped-out), (iii) became an incident 
Table 1. Baseline description of symptom data collection methods for each study.

\begin{tabular}{|c|c|c|c|c|c|c|c|c|c|}
\hline \multirow[t]{2}{*}{$\begin{array}{l}\text { Study } \\
\text { groups }\end{array}$} & \multirow[t]{2}{*}{$\begin{array}{l}\text { Assessment } \\
\text { type }\end{array}$} & \multirow[t]{2}{*}{ Method } & \multirow[t]{2}{*}{ Symptom type ${ }^{a}$} & \multirow[t]{2}{*}{$\begin{array}{l}\text { Digits with } \\
\text { symptoms }^{\text {b }}\end{array}$} & \multirow{2}{*}{$\begin{array}{l}\text { Symptoms } \\
\text { in one or } \\
\text { more digits }\end{array}$} & \multirow{2}{*}{$\begin{array}{c}\text { Baseline } \\
\text { assessment } \\
\text { of symptoms }\end{array}$} & \multirow{2}{*}{$\begin{array}{l}\text { Follow-up } \\
\text { symptom } \\
\text { assessments }\end{array}$} & \multicolumn{2}{|c|}{$\begin{array}{c}\text { Symptom assessments } \\
\text { per subject }\end{array}$} \\
\hline & & & & & & & & Mean & Range \\
\hline$A$ & Survey & Hand diagram & $\mathrm{N}, \mathrm{T}, \mathrm{B}, \mathrm{P}$ & $(1 / 2 / 3)$ & Yes & Yes & Annually & 2.7 & $1-3$ \\
\hline B & Survey & Hand diagram & $\begin{array}{l}(\mathrm{B}),(\mathrm{N} / \mathrm{T}) \\
(\mathrm{N} / \mathrm{T} / \mathrm{P})\end{array}$ & $(1 / 2 / 3)$ & Yes & Yes & Every 4 months & 7.2 & $1-11$ \\
\hline C & Interview & $\begin{array}{l}\text { Type and location } \\
\text { of symptoms }\end{array}$ & (N/T/B/P) & $(1 / 2 / 3)$ & Yes & Yes & Every 4 months & 4.6 & $1-12$ \\
\hline D & Interview & $\begin{array}{l}\text { Type and location } \\
\text { of symptoms }\end{array}$ & $\mathrm{N}, \mathrm{T}, \mathrm{B}, \mathrm{P}$ & $(1 / 2 / 3)$ & Yes & Yes & Weekly & 45.6 & $1-147$ \\
\hline$E$ & Interview & $\begin{array}{l}\text { Type and location } \\
\text { of symptoms }\end{array}$ & $(\mathrm{N} / \mathrm{T})$ & $1,2,3$ & Yes & Yes & Monthly & 45.3 & $1-75$ \\
\hline $\mathrm{F}$ & Survey & Hand diagram & $(\mathrm{N} / \mathrm{T}),(\mathrm{B} / \mathrm{P})$ & $(1 / 2 / 3)$ & Yes & Yes & $\begin{array}{l}6 \& 18 \& 36 \\
\text { months }\end{array}$ & 4.6 & $1-5$ \\
\hline
\end{tabular}

${ }^{a}$ Symptom type: N=numbness, T=tingling, B=burning, $P=$ pain; combined descriptors listed in parentheses ( )

${ }^{\mathrm{b}}$ Digit number: $1=$ thumb, $2=$ =index finger, $3=$ long finger

Table 2. Baseline description of nerve conduction studies data collection methods for each study. [EDS=electrodiagnostic studies; NCS=nerve conduction study; $\mathrm{n} / \mathrm{a}=$ not available]

\begin{tabular}{|c|c|c|c|c|c|c|c|c|c|c|c|}
\hline \multirow[t]{2}{*}{$\begin{array}{l}\text { Study } \\
\text { groups }\end{array}$} & \multirow[t]{2}{*}{$\begin{array}{l}\text { EDS } \\
\text { device }\end{array}$} & \multirow[t]{2}{*}{$\begin{array}{l}\text { Temperature } \\
\text { location } \\
\text { recording }\end{array}$} & \multirow{2}{*}{$\begin{array}{l}\text { Trigger } \\
\text { tempera- } \\
\text { ture for } \\
\text { hand } \\
\text { warm } \\
\end{array}$} & \multirow{2}{*}{$\begin{array}{l}\text { Electrode } \\
\text { distance } \\
\text { measure- } \\
\text { ment }\end{array}$} & \multirow[t]{2}{*}{$\begin{array}{l}\text { Sensory } \\
\text { latency } \\
\text { record- } \\
\text { ing }\end{array}$} & \multirow{2}{*}{$\begin{array}{l}\text { Median } \\
\text { nerve } \\
\text { test } \\
\text { digit }\end{array}$} & \multirow[t]{2}{*}{$\begin{array}{l}\text { Ulnar } \\
\text { nerve test } \\
\text { digit }\end{array}$} & \multirow{2}{*}{$\begin{array}{l}\text { Baseline } \\
\text { assess- } \\
\text { ment of } \\
\text { NCS }\end{array}$} & \multirow[t]{2}{*}{$\begin{array}{c}\text { Follow-up frequency } \\
\text { of NCS }\end{array}$} & \multicolumn{2}{|c|}{$\begin{array}{l}\text { Frequency } \\
\text { of NCS per } \\
\text { subject }\end{array}$} \\
\hline & & & & & & & & & & Mean & Range \\
\hline A & $\begin{array}{l}\text { XLTEC } \\
\text { Neuromax } \\
1002\end{array}$ & Mid-palm & $32^{\circ} \mathrm{C}$ & $\begin{array}{l}\text { Pre- } \\
\text { measured a }^{\text {a }}\end{array}$ & Peak & Index & Small & Yes & Annually & 2.7 & $1-3$ \\
\hline B & $\begin{array}{l}\text { Cadwell } \\
\text { Sierra II }\end{array}$ & Dorsal hand & $32^{\circ} \mathrm{C}$ & $\begin{array}{l}\text { Pre- } \\
\text { measured a }\end{array}$ & Peak & Index & Small & Yes & Annually & 3.1 & $1-4$ \\
\hline C & NCstat & Volar wrist & $31^{\circ} \mathrm{C}$ & $\begin{array}{l}\text { Directly } \\
\text { measured }\end{array}$ & Peak & Long & Small & Yes & $\begin{array}{l}\text { Annually and symptoms } \\
\text { at } 4 \text { months triggered } \\
\text { NCS }\end{array}$ & 2.4 & $1-6$ \\
\hline D & $\begin{array}{l}\text { Teca } \\
\text { Sapphire2P }\end{array}$ & Mid-palm & $32^{\circ} \mathrm{C}$ & $\begin{array}{l}\text { Directly } \\
\text { measured }\end{array}$ & Onset & Index & Small & $\begin{array}{l}\text { If trig- } \\
\text { gered by } \\
\text { symptoms }\end{array}$ & $\begin{array}{l}\text { Weekly symptoms trig- } \\
\text { gered exam; symptoms } \\
\text { of median nerve trig- } \\
\text { gered NCS }\end{array}$ & 1.4 & $1-4$ \\
\hline E & $\begin{array}{l}\text { TECA } \\
\text { Synergy }\end{array}$ & Dorsal hand & $\begin{array}{l}30^{\circ} \mathrm{C} / \\
32^{\circ} \mathrm{Cb}\end{array}$ & $\begin{array}{l}\text { Directly } \\
\text { measured }\end{array}$ & Peak & Long & Small & Yes & $\begin{array}{l}\text { All tested at } 4 \& 7 \text { years } \\
\text { and monthly symptoms } \\
\text { triggered NCS }\end{array}$ & 3.3 & $1-11$ \\
\hline $\mathrm{F}$ & NCstat & Volar wrist & $n / a$ & $\begin{array}{l}\text { Directly } \\
\text { measured }\end{array}$ & Peak & Long & Small & Yes & $\begin{array}{l}\text { All tested between } \\
3-5 \text { years }\end{array}$ & 1.8 & $1-2$ \\
\hline
\end{tabular}

a Sensory test distance- $14 \mathrm{~cm}$, motor test distance-8cm.

${ }^{\mathrm{b}} 700$ subjects were tested with hand warming triggered $<30^{\circ} \mathrm{C}$; all others were tested with 32 degrees.

CTS case, or (iv) became an incident polyneuropathy case. Subjects were considered to have met the CTS case definition of median nerve symptoms and abnormal EDS on the date they met symptom criteria up to four months prior to the date of the confirmatory EDS. One study (D) used the presence of characteristic symptoms to trigger EDS testing. Three studies (A, B, F) performed EDS testing for all subjects at predetermined time points, regardless of reported symptoms on interim surveys, and two studies (C and E) performed EDS testing at predetermined time points as well as when triggered by symptoms. All analyses were conducted using STATA (StataCorp, College Station, TX, USA).

\section{Results}

A total of 4321 subjects were enrolled across the six studies (tables 3A and 3B). Education, race and ethnicity, age, and body mass index differed across study samples. The percentage of college graduates ranged from $0.7-20.6 \%$, and the percentage of Caucasian study subjects ranged from $8.2-92.7 \%$. While the pooled study sample overall had nearly equal numbers of males and females, the proportion of male subjects ranged from $36-65 \%$ across individual studies. Mean age at enrollment ranged from 30.8-43.4 years across studies. The 
average duration of employment was 6.2 years at baseline; while most studies enrolled current workers, one study (F) enrolled only newly hired workers who were generally younger. The majority of the workers were from manufacturing companies $(64.0 \%)$ while others worked in construction, agriculture, healthcare, technical professions, and service work. The manufactured products included vehicles, household appliances, furniture, artificial stone, metal products, machinery, books, textiles, and dairy and food products.

Table 4 shows the prevalence of symptoms, median mononeuropathy, and CTS at baseline. Overall, 15.2\% of the subjects met the hand symptom criteria at baseline, with a range of $6.0-24.0 \%$ across the research studies, with the lowest frequency among subjects from study F, which recruited the youngest workers with the shortest job tenure at the time of evaluation. Overall, $31.0 \%$ of subjects had an abnormal EDS at baseline. Polyneuropathy, defined as those with abnormal ulnar sensory latency in addition to CTS, was uncommon (1.4\%). Prevalent CTS (ie, those meeting the pooled study CTS case definition or having a prior history of CTR) ranged from $2.6-14.0 \%$ at baseline across studies with $7.8 \%$ of the pooled cohort meeting the CTS case definition of symptoms and EDS abnormalities. Prevalent CTS was higher among females than males [10.0\%, 95\% confidence interval $(95 \% \mathrm{CI}) 8.7-11.3 \%$ versus $5.8 \%, 95 \%$ CI $4.8-6.8 \%$ ]. The proportion of prevalent CTS increased with older age categories: $<30$ (3.7\%), $30-<40(6.4 \%), 40-<50(10.7 \%)$, and $\geq 50$ years $(11.9 \%)$.

After excluding prevalent cases of CTS and polyneuropathy as well as the subjects with no follow-up measurements, 3515 workers were eligible for inclusion in the analysis of CTS incidence (figure 2). In the pooled analysis, 204 incident cases of CTS were observed across 8833 total person-years of observation, resulting in an incidence rate of 2.3 cases per 100 person-years (table 5). The CTS incidence rate varied considerably across studies, from 0.7 cases per 100 person-years (Study F) to 5.6 cases per 100 person-years (Study A). In the pooled cohort, the incidence rate of CTS symptoms was 9.3 per 100 person-years and the incidence rate of median mononeuropathy was 4.0 per 100 person-years.

Of the 159 subjects in the incidence analysis who became symptomatic but did not receive a follow-up EDS within four months, most came from studies $\mathrm{E}$ and $\mathrm{F}(\mathrm{N}=143)$. Because some of these subjects would have likely met the pooled study criteria for CTS if they had been administered EDS, the observed incidence estimates for these two studies is likely an underestimate of the true incidence. To explore the extent of such underestimation, we first calculated the proportions of symptomatic subjects who met the EDS case definition for median mononeuropathy separately for each study. The propor- tions of symptomatic subjects who met the EDS criteria for median mononeuropathy were $34.2 \%$ and $28.6 \%$ for Study E and F, respectively. From this information, we calculated the number of subjects with positive symptoms expected to have met the CTS case definition, had an EDS been obtained. An estimated additional 27 and 18 incidence cases would have been observed for Study $\mathrm{E}$ and $\mathrm{F}$, respectively. These additional cases would have increased the adjusted incident rates to 3.6 and 1.2 per 100 person-years for Study E and F, respectively, rates more consistent with the other study groups.

\section{Discussion}

By pooling data from six research studies, more stable estimates of CTS frequency were possible than were estimates from each of the individual studies. In order to best characterize CTS frequency, a pooled study case definition was created that required both characteristic symptoms and EDS confirmation of median nerve mononeuropathy at the wrist. The prevalence of CTS was $7.8 \%$ among the members of this pooled cohort of 4321 mostly industrial workers with higher proportions among females and older age categories. Incident CTS was observed among 5.8\% of 3515 workers, who contributed any person time to the analysis resulting in an incidence rate of 2.3 per 100 person-years.

Previous studies of CTS have reported widely varying prevalence and incidence rates of CTS. While CTS rates depend on the physical exposures and other characteristics of the population under study, they are also affected by the study design and CTS case definitions used to define the disease (40). Case definitions based on symptoms alone lead to higher estimates of disease prevalence compared to definitions requiring both symptoms and EDS confirmation (37). Cross-sectional studies using case definitions based solely on characteristic hand symptoms of CTS have reported prevalence proportions of CTS from $11-31 \%(8,41)$, which are similar to the prevalence of symptoms of $15.2 \%$ for this pooled study. Yet lower prevalence proportions between 3-11\% were found for studies with case definitions requiring both symptoms and nerve conduction abnormalities $(8,12)$, similar to the $7.8 \%$ prevalence observed in the current pooled analysis. Case definitions that include symptoms and median mononeuropathy abnormalities are considered to be more specific for CTS $(11,34,42,43)$.

The $7.8 \%$ prevalence of CTS in our study is comparable to those reported in past studies. The cohort comprised of new hires (Study F) had the lowest CTS prevalence $(2.6 \%)$. Prevalent CTS in working populations also differ by the type of work. Studies of manufacturing workers that used a case definition of 
Table 3A. Baseline demographics and characteristics of categorical variables of each study.

\begin{tabular}{|c|c|c|c|c|c|c|c|}
\hline & \multicolumn{6}{|c|}{ Study groups } & \multirow[b]{2}{*}{$\begin{array}{c}\text { Total } \\
\mathrm{N}=4321\end{array}$} \\
\hline & $\begin{array}{c}A \\
\mathrm{~N}=482\end{array}$ & $\begin{array}{c}\mathrm{B} \\
\mathrm{N}=720\end{array}$ & $\begin{array}{c}\mathrm{C} \\
\mathrm{N}=447\end{array}$ & $\begin{array}{c}D \\
N=346\end{array}$ & $\begin{array}{c}E \\
N=1219\end{array}$ & $\begin{array}{c}F \\
N=1107\end{array}$ & \\
\hline & $\%$ & $\%$ & $\%$ & $\%$ & $\%$ & $\%$ & $\%$ \\
\hline \multicolumn{8}{|l|}{ Gender } \\
\hline Male & 55.6 & 51.9 & 64.0 & 47.7 & 34.0 & 65.0 & 51.5 \\
\hline Female & 44.0 & 48.1 & 36.0 & 52.3 & 66.0 & 35.0 & 48.4 \\
\hline Missing values & 0.4 & 0.0 & 0.0 & 0.0 & 0.1 & 0.0 & 0.1 \\
\hline \multicolumn{8}{|l|}{ Hand dominance } \\
\hline Right hand dominant & 90.5 & 91.7 & 95.5 & 88.2 & 92.0 & 89.4 & 91.2 \\
\hline Missing values & 0.4 & 0.0 & 1.6 & 0.0 & 0.0 & 0.5 & 0.3 \\
\hline $\begin{array}{l}\text { Education } \\
\text { Some high school or less }\end{array}$ & 52 & 168 & 694 & 20 & 112 & 76 & 158 \\
\hline $\begin{array}{l}\text { Some high school or less } \\
\text { Graduated high school }\end{array}$ & $\begin{array}{r}0.2 \\
81.1\end{array}$ & 73.8 & 28.2 & 92.8 & 82.7 & 71.7 & 73.4 \\
\hline College graduate or above & 13.3 & 9.4 & 0.7 & 4.0 & 3.7 & 20.6 & 9.8 \\
\hline Missing values & 0.4 & 0.0 & 1.8 & 1.2 & 2.5 & 0.1 & 1.0 \\
\hline \multicolumn{8}{|l|}{ Ethnicity } \\
\hline Caucasian & 68.7 & 59.4 & 8.3 & 91.9 & 42.8 & 61.2 & 53.5 \\
\hline Hispanic & 3.7 & 13.2 & 83.2 & 0.9 & 9.8 & 0.7 & 14.2 \\
\hline African American & 22.8 & 3.9 & 1.6 & 4.0 & 4.0 & 34.1 & 13.6 \\
\hline Asian & 1.2 & 17.9 & 1.3 & 2.3 & 1.5 & 2.1 & 4.4 \\
\hline Other & 1.2 & 5.6 & 2.2 & 0.0 & 3.2 & 1.6 & 2.6 \\
\hline Missing values & 2.3 & 0.0 & 3.4 & 0.9 & 38.7 & 0.3 & 11.7 \\
\hline \multicolumn{8}{|l|}{ Current medical condition } \\
\hline Diabetes & 4.6 & 3.6 & 6.3 & 1.7 & 5.3 & 2.6 & 4.1 \\
\hline Rheumatoid arthritis & 1.2 & 1.1 & 2.5 & 1.2 & 4.0 & 1.3 & 2.1 \\
\hline Thyroid disease (hyper/hypo) & 7.3 & 5.0 & 0.9 & 6.4 & 6.9 & 2.4 & 4.8 \\
\hline Pregnancy & 0.2 & 1.4 & 0.2 & 0.3 & 0.6 & - & 0.5 \\
\hline
\end{tabular}

Table 3B. Baseline demographics and characteristics of continuous variables of each study. [SD=standard deviation.]

\begin{tabular}{|c|c|c|c|c|c|c|c|c|c|c|c|c|c|c|}
\hline & \multicolumn{12}{|c|}{ Study groups } & & \\
\hline & \multicolumn{2}{|c|}{$\begin{array}{c}A \\
\mathrm{~N}=482\end{array}$} & \multicolumn{2}{|c|}{$\begin{array}{c}\mathrm{B} \\
\mathrm{N}=720\end{array}$} & \multicolumn{2}{|c|}{$\underset{\mathrm{N}=450}{\mathrm{C}}$} & \multicolumn{2}{|c|}{$\begin{array}{c}D \\
N=346\end{array}$} & \multicolumn{2}{|c|}{$\begin{array}{c}E \\
N=1220\end{array}$} & \multicolumn{2}{|c|}{$\begin{array}{c}F \\
N=1107\end{array}$} & \multicolumn{2}{|c|}{$\begin{array}{c}\text { Total } \\
\mathrm{N}=4321\end{array}$} \\
\hline & Mean & SD & Mean & $\mathrm{SD}$ & Mean & SD & Mean & SD & Mean & SD & Mean & SD & Mean & SD \\
\hline Age at enrollment & 41.1 & 10.8 & 39.5 & 10.9 & 38.6 & 11.2 & 43.4 & 10.0 & 42.7 & 11.4 & 30.9 & 10.3 & 38.5 & 11.8 \\
\hline Body mass index $\left(\mathrm{kg} / \mathrm{m}^{2}\right)$ & 29.6 & 6.5 & 27.3 & 5.8 & 28.7 & 4.7 & 27.5 & 5.5 & 29.4 & 6.7 & 28.5 & 6.5 & 28.6 & 6.3 \\
\hline Years employed at enrollment & 6.7 & 4.5 & 6.3 & 7.0 & 6.1 & 5.7 & 16.4 & 11.1 & 10.0 & 9.4 & 0.2 & 0.3 & 6.5 & 8.3 \\
\hline
\end{tabular}

symptoms and abnormal EDS have reported prevalence between $5.6-11.9 \%(6,44)$. High proportions have also been observed among construction $(8.2 \%)$, poultry $(8.9 \%)$ and dairy workers $(16.6 \%)(45-47)$. The pooled cohort in the current study consisted largely of workers from manufacturing (64\%) with subsets from service and construction industries as well as jobs of lower hand intensity including clerical and technical positions.

CTS incidence rates in previous studies have depended in part on the use of active versus passive surveillance methods to identify cases. Passive surveillance approaches, such as the use of workers' compensation data, results in observed annual CTS incidence rates that range from $0.04-0.2$ per 100 person-years, varying by occupation or industry $(13,21)$. Active surveillance approaches, such as the few longitudinal studies that screened all members of a defined cohort for symptoms and nerve conduction abnormalities, results in higher observed CTS incident rates. Gerr and colleagues screened clerical workers on a weekly basis and observed an annual incidence of CTS of 0.91 per 100 person-years (48). A prospective study of industrial and clerical workers showed an incidence of 1.24 per 100 person-years (14). The current study found an incidence rate of 2.3 per 100 person-years in the pooled cohort. More of the workers represented in the pooled cohort were employed in jobs requiring hand-intensive activities than in the Gerr (48) or Gell (14) studies. The frequent screening of workers over time provides for the most complete monitoring for the development of symptoms and opportunities for confirmation with electrodiagnostic testing.

The strengths of this analysis include the detailed comparisons of the data collection methods for CTS case 
Table 4. Prevalence of carpal tunnel syndrome (CTS) of the dominant hand at baseline for each study. [CTR=carpal tunnel release or surgery; MUDS=median-ulnar sensory difference; $95 \% \mathrm{Cl}=95 \%$ confidence interval]

\begin{tabular}{|c|c|c|c|c|c|c|c|c|c|c|c|c|c|c|c|}
\hline & \multicolumn{15}{|c|}{ Study groups } \\
\hline & \multicolumn{2}{|c|}{$\begin{array}{c}A \\
\mathrm{~N}=482\end{array}$} & \multicolumn{2}{|c|}{$\begin{array}{c}B \\
N=720\end{array}$} & \multicolumn{2}{|c|}{$\begin{array}{c}\mathrm{C} \\
\mathrm{N}=447\end{array}$} & \multicolumn{2}{|c|}{$\begin{array}{c}D \\
N=346\end{array}$} & \multicolumn{2}{|c|}{$\begin{array}{c}E \\
N=1219\end{array}$} & \multicolumn{2}{|c|}{$\begin{array}{c}F \\
N=1107\end{array}$} & \multicolumn{3}{|c|}{$\begin{array}{c}\text { Total } \\
\mathrm{N}=4321\end{array}$} \\
\hline & $\mathrm{N}$ & $\%$ & $\mathrm{~N}$ & $\%$ & $\mathrm{~N}$ & $\%$ & $\mathrm{~N}$ & $\%$ & $\mathrm{~N}$ & $\%$ & $\mathrm{~N}$ & $\%$ & $\mathrm{~N}$ & $\%$ & $95 \% \mathrm{Cl}$ \\
\hline Prevalent polyneuropathy a & 9 & 1.9 & 2 & 0.3 & 3 & 0.7 & 0 & 0 & 41 & 3.8 & 3 & 0.3 & 58 & 1.4 & $1.0-1.7$ \\
\hline Median nerve symptoms ${ }^{b}$ & 105 & 21.8 & 107 & 14.9 & 56 & 12.5 & 30 & 8.7 & 293 & 24.0 & 66 & 6.0 & 657 & 15.2 & $14.2-16.3$ \\
\hline Median mononeuropathy c & 232 & 48.5 & 186 & 25.8 & 116 & 26.3 & 23 & 6.6 & 484 & 45.6 & 193 & 17.6 & 1234 & 31.0 & $29.6-32.4$ \\
\hline CTS case definition ${ }^{d}$ & 60 & 12.4 & 45 & 6.3 & 23 & 5.1 & 21 & 6.1 & 125 & 10.3 & 29 & 2.6 & 303 & 7.1 & $6.3-7.8$ \\
\hline $\begin{array}{l}\text { Prior CTR reported at } \\
\text { baseline }\end{array}$ & 5 & 1.0 & 3 & 0.4 & 6 & 1.3 & 1 & 0.3 & 22 & 1.8 & 0 & 0.0 & 37 & 0.9 & $0.6-1.1$ \\
\hline Prevalent CTS cases e & 64 & 13.3 & 48 & 6.7 & 29 & 6.6 & 22 & 6.4 & 146 & 14.0 & 29 & 2.6 & 338 & 7.8 & $7.1-8.6$ \\
\hline
\end{tabular}

a Polyneuropathy criteria: onset sensory-recorded wave - CTS case definition AND ulnar sensory latency $>3.18 \mathrm{~ms}$; peak sensory-recorded wave CTS case definition AND ulnar sensory latency > $3.68 \mathrm{~ms}$.

${ }^{\mathrm{b}}$ Median nerve symptom criteria: numbness, tingling, burning or pain in $\geq 1$ digits (thumb, index, long).

c Median neuropathy critera: onset sensory-recorded wave - median nerve symptoms AND [(median sensory latency >3.2 ms or absent) or median motor latency $>4.5 \mathrm{~ms}$ or MUDS $>0.85 \mathrm{~ms}$ ]; peak sensory-recorded wave - median nerve symptoms and [(median sensory latency $>3.7 \mathrm{~ms}$ or absent) or median motor latency $>4.5 \mathrm{~ms}$ or MUDS $>0.85 \mathrm{~ms}]$.

d CTS case definition criteria: median nerve symptoms and median neuropathy of the dominant hand

e Prevalent CTS case: CTS case definition or prior CTR reported at baseline.

Table 5. Incidence of carpal tunnel syndrome (CTS) of the dominant hand for each study. [EDS=electrodiagnostic studies; IR=incident rate; $95 \% \mathrm{Cl}=95 \%$ confidence interval]

\begin{tabular}{|c|c|c|c|c|c|c|c|c|c|c|c|c|c|c|c|}
\hline & \multicolumn{15}{|c|}{ Study Groups } \\
\hline & \multicolumn{2}{|c|}{ A } & \multicolumn{2}{|c|}{ B } & \multicolumn{2}{|c|}{ C } & \multicolumn{2}{|c|}{ D } & \multicolumn{2}{|c|}{$E$} & \multicolumn{2}{|c|}{$\mathrm{F}$} & \multicolumn{3}{|c|}{ Total } \\
\hline & $\mathrm{N}$ & $\mathrm{IR}$ & $\mathrm{N}$ & $\overline{\mathrm{IR}}$ & $\mathrm{N}$ & $\overline{I R}$ & $\mathrm{~N}$ & $\mathrm{IR}$ & $\mathrm{N}$ & $\overline{I R}$ & $\mathrm{~N}$ & $\overline{\mathrm{IR}}$ & $\mathrm{N}$ & $\mathrm{IR}$ & $95 \% \mathrm{Cl}$ \\
\hline Original population & 482 & & 720 & & 447 & & 346 & & 1219 & & 1107 & & 4321 & & \\
\hline Sample at risk for incident CTS & 357 & & 592 & & 392 & & 294 & & 884 & & 996 & & 3515 & & \\
\hline CTS case definition a & 34 & & 47 & & 17 & & 12 & & 70 & & 24 & & 204 & & \\
\hline Person time (in person years) & 605 & & 1145 & & 503 & & 244 & & 2681 & & 3657 & & 8833 & & \\
\hline Censored due to polyneuropathy ${ }^{b}$ & 6 & & 0 & & 0 & & 0 & & 20 & & 2 & & 28 & & \\
\hline $\begin{array}{l}\text { Censored due to symptoms and no } \\
\text { EDS }{ }^{c}\end{array}$ & 5 & & 9 & & 2 & & 0 & & 79 & & 64 & & 159 & & \\
\hline Incident rate (per 100 person years) & & 5.6 & & 4.1 & & 3.4 & & 4.9 & & 2.6 & & 0.7 & & 2.3 & $2.0-2.7$ \\
\hline
\end{tabular}

definitions used by six distinct studies and the creation of a single large dataset for use in the pooled analyses. The results of this pooling have produced a well-characterized and diverse cohort of 4321 workers with a large number of incident and prevalent CTS cases. These data provide adequate power for future exposure response analysis to adjust for confounding and assess interactions. The geographic variability and variety of work types included in this pooled cohort will increase the generalizability of future analyses of these data. This pooled dataset will enable future studies that can address some of the limitations seen in many past studies, including reliance on retrospective methods $(49,50)$, small sample sizes, non-representative samples of workers and industries, lack of adequate baseline assessments in the few reported cohort studies, and lack of objective outcomes measures including nerve conduction measurements, the definitive physiological indicator of CTS $(51,52)$.

Several important challenges were encountered when pooling the health outcomes data for this study. Test procedures varied across studies. Hand temperature measurements were recorded in different locations of the hand and the warming procedures were not uniform. We attempted to adjust for this difference by normalizing results for temperature based on the data from within each study. The use of six nerve testing devices may have introduced an instrument bias since reliability testing between devices was not performed, However the devices used in the six studies are all widely accepted and commonly used in clinical and research settings. Measurements taken with the portable nerve testing device used at two studies (NC-stat) have been shown to 


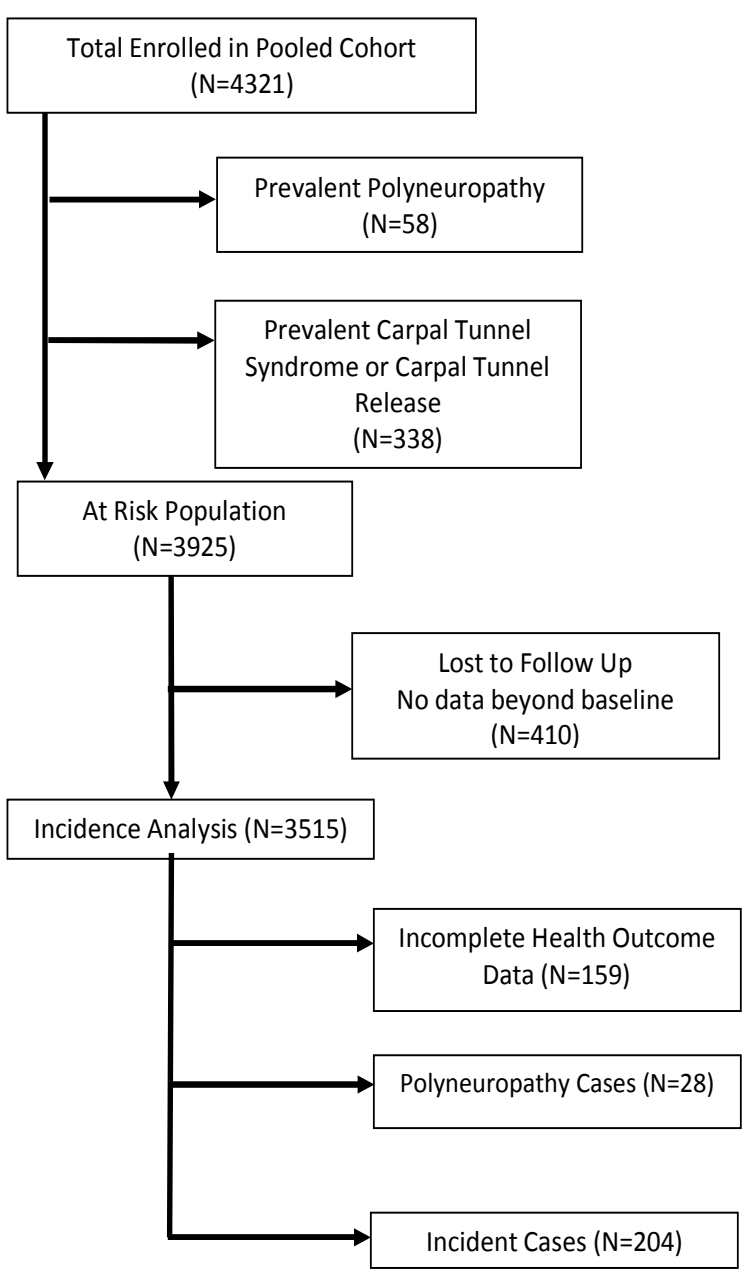

Figure 2. Selection of sample for the incidence analysis

correlate well with traditional nerve testing $(32,53)$. The differences in frequency of symptom assessment and nerve conduction studies (NCS) between studies may have affected the sensitivity of case detection between studies. Because symptoms of CTS can vary over time, studies that assessed symptoms more frequently may have detected more cases than those assessing symptoms less frequently. The symptom data were collected across all studies using the same symptom qualities (numbness, tingling, burning, or pain), and location, though symptom questions were posed to subjects in different ways.

As described above, there were differences among the six studies in the frequency of subject assessment and the protocols used to collect symptom and EDS results. However, important similarities across these research studies allowed us to create a common case definition of CTS for use in a pooled longitudinal analysis. This large pooled cohort allowed us to estimate both prevalence and incidence rates of CTS in this large and varied sample of working men and women. Most importantly, these pooled CTS outcomes data can now be paired with detailed individual exposure data from the same cohort to allow for a powerful analysis of exposure-response relationships between work-related and individual factors and CTS incidence.

\section{Acknowledgments}

This study was supported by research funding from the Center for Disease Control / NIOSH (5R01OH009712) and from the National Center for Research Resources (NCRR), a component of the National Institutes of Health (NIH), and NIH Roadmap for Medical Research (UL1 RR024992). The findings and conclusions in this report are those of the authors and do not necessarily represent the views of NIOSH. We would like to acknowledge the efforts of the large number of research technician, assistants, and any other personnel from each of the research study groups that made the collection of the data presented in this manuscript possible.

No co-author reported having a direct financial interest in the results of the research supporting this article.

\section{References}

1. Stapleton MJ. Occupation and carpal tunnel syndrome. Anz Journal of Surgery. 2006 Jun;76(6):494-6. http://dx.doi. org/10.1111/j.1445-2197.2006.03770.x.

2. US Bureau of Labor and Statistics, US Department of Labor, 2011. Nonfatal occupational injuries and illnesses requiring days away from work, 2010. USDL report number: 11-1612. Retrieved October 3, 2012, from: http://www.bls.gov/news. release/osh2.nr0.htm

3. Foley M, Silverstein B, Polissar N. The economic burden of carpal tunnel syndrome: long-term earnings of CTS claimants in Washington State. Am J Ind Med. 2007 Mar;50(3):155-72. http://dx.doi.org/10.1002/ajim.20430.

4. Faucett J, Blanc, P Yelin E. The impact of carpal tunnel syndrome on work status: Implications of job characteristics for staying on the job. J Occup Rehab. 2000;10(1):55-69. http://dx.doi.org/10.1023/A:1009441828933.

5. Roquelaure Y, Mariel J, Dano C, Fanello S, PenneauFontbonne D. Prevalence, incidence and risk factors of carpal tunnel syndrome in a large footwear factory. Int J Occup Med Environ Health. 2001;14(4): 357-67.

6. Maghsoudipour M, Moghimi S, Dehghaan F, Rahimpanah A Association of occupational and non-occupational risk factors with the prevalence of work related carpal tunnel syndrome. J Occup Rehabil. 2008 Jun;18(2):152-6. http://dx.doi. org/10.1007/s10926-008-9125-4. 
7. Gorsche RG, Wiley JP, Renger RF, Brant RF, Gemer TY, Sasyniuk TM. Prevalence and incidence of carpel tunnel syndrome in a meat packing plant. Occup Environ Med. 1999 Jun;56(6):417-22. http://dx.doi.org/10.1136/oem.56.6.417.

8. Silverstein BA, Fan ZJ, Banauto DK, Bao S, Smith CK, Howard N, et al. The natural course of carpal tunnel syndrome in a working population. Scand J Work Environ Health. 2010 Sep;36(5):384-93. http://dx.doi.org/10.5271/sjweh.2912.

9. Tanaka S, Wild DK, Seligman PJ, Halperin WE, Behrens VJ, Putz-Anderson V. Prevalence and work-relatedness of selfreported carpal tunnel syndrome among U.S. workers: analysis of the Occupational Health Supplement data of 1988 National Health Interview Survey. Am J Ind Med. 1995 Apr;27(4):45170. http://dx.doi.org/10.1002/ajim.4700270402.

10. Stevens JC, Sun S, Beard CM, Ofallon WM, Kurland LT. Carpal tunnel syndrome in Rochester, Minnesota, 1961 to 1980. Neurology. 1988 Jan;38(1):134-8. http://dx.doi. org/10.1212/WNL.38.1.134.

11. DeKrom M, Knipschild PG, Kester ADM, Thijs CT, Boekkooi PF, Spaans F. Carpal tunnel syndrome - prevalence in the general-population. J Clin Epidemiol. 1992 Apr;45(4):373-6. http://dx.doi.org/10.1016/0895-4356(92)90038-O.

12. Atroshi I, Gummesson C, Johnsson R, Ornsein E, Ranstam J, Rosen I. Prevalence of carpal tunnel syndrome in a general population. JAMA. 1999 Jul 14;282(2):153-8. http://dx.doi. org/10.1001/jama.282.2.153.

13. Franklin GM, Haug J, Heyer N, Checkoway H, Peck N. Occupational carpal tunnel syndrome in Washington State, 1984-1988. Am J Public Health. 1991 Jun;81(6):741-6. http:// dx.doi.org/10.2105/AJPH.81.6.741.

14. Gell N, Werner RA, Franzblau A, Ulin SS, Armstrong TJ. A longitudinal study of industrial and clerical workers: incidence of carpal tunnel syndrome and assessment of risk factors. J Occup Rehabil. 2005 Mar;15(1):47-55. http://dx.doi. org/10.1007/s10926-005-0873-0.

15. Bonfiglioli R, Mattioli S, Armstrong T, Graziosi F, Marinelli F, Farioli A, et al. Validation of the ACGIH TLV for hand activity level in the OCTOPUS cohort: a two-year longitudinal study of carpal tunnel syndrome. Scand J Work Environ Health. 2012 Jul 2. [Epub ahead of print]. http://dx.doi.org/10.5271/ sjweh.3312.

16. Van Rijn R, Huisstede B, Koes B, Burdorf A. Associations between work-related factors and carpal tunnel syndromeA systematic review. Scand J Work Environ Health. 2009;35(1):19-36. http://dx.doi.org/10.5271/sjweh.1306.

17. Palmer K. Carpal tunnel syndrome: The role of occupational factors. Best Practice \& Research Clinical Rheumatology. 2011;25:15-29. http://dx.doi.org/10.1016/j. berh.2011.01.014.

18. Nathan P, Istvan JA, Meadows KD. A longitudinal study of predictors of research-defined carpal tunnel syndrome in industrial workers: findings at 17 years. J Hand Surg $(\mathrm{Br})$. 2005;38B(6):593-8.

19. Roquelaure Y, Ha C, Rouillon C, Fouquet N, Leclerc A, Descatha A, Touranchet A, Goldberg m, Imbernon E, and 83
Occupational Physicains of The Pays de La Loire Region. Risk factors for upper-extremity musculoskeletal disorders in the working population. Arthritis Rheum. 2009 Oct;61(10):142534. http://dx.doi.org/10.1002/art.24740.

20. Nordstrom DL, Vierkant RA, DeStefano F, Layde PM. Risk factors for carpal tunnel syndrome in a general population. Occup Environ Med. 1997 Oct;54(10):734-40. http://dx.doi. org/10.1136/oem.54.10.734.

21. Jenkins PJ, Srikantharajah D, Duckworth AD, Watts AC, McEachan JE. Carpal tunnel syndrome: the association with occupation at a population level. J Hand Surg Eur Vol. 2013 Jan;38(1):67-72. http://dx.doi. org/10.1177/1753193412455790.

22. Frost P, Andersen JH, Nielsen VK. Occurrence of carpal tunnel syndrome among slaughterhouse workers. Scand J Work Environ Health. 1998 Aug;24(4):285-92. http://dx.doi. org/10.5271/sjweh.322.

23. Moore JS, Garg A. Upper extremity disorders in a pork processing plant: relationship between job risk factors and morbidity. Am Ind Hyg Assoc J. 1994 Aug;55(8):703-15. http://dx.doi.org/10.1080/15428119491018592.

24. Roquelaure Y, Mechali S, Dano C, Fanello S, Benetti F, Bureau $\mathrm{D}$, et al. Occupational and personal risk factors for carpal tunnel syndrome in industrial workers. Scand J Work Environ Health. 1997;23:364-9. http://dx.doi.org/10.5271/sjweh.233.

25. Garg A, Hegmann K, Wertsch J, Kapellusch J, Thiese M, Bloswick D, et al. The WISTAH hand study: A prospective cohort study of distal upper extremity musculoskeletal disorders. BMC Musculoskeletal Disorders. 2012 Jun 6;13:90. http://dx.doi.org/10.1186/1471-2474-13-90.

26. Ioannidis JP, Lau J. Pooling research results: benefits and limitations of meta-analysis. Jt Comm J Qual Improv. 1999 Sep;25(9):462-9.

27. Kapellusch J, Garg A, Bao S, Silverstein B, Burt S, Dale A, Evanoff B, Gerr F, Harris-Adamson C, Hegmann K, Merlino L, Rempel D. Pooling Job Physical Exposure Data from Multiple Sites in a Study of Carpal Tunnel Syndrome. Ergonomics (accepted for publication).

28. Katz JN, Stirrat CR, Larson MG, Fossel AH, Eaton HM, Liang MH. A self-administered hand symptom diagram for the diagnosis and epidemiologic study of carpal tunnel syndrome. J Rheumatol. 1990 Nov;17(11):1495-8.

29. Franzblau A, Werner RA, Albers JW, Grant CL, Olinski D, Johnston E. Workplace surveillance for carpal tunnel syndrome using hand diagrams. J Occup Rehabil. 1994 Dec;4(4):185-98. http://dx.doi.org/10.1007/BF02331615.

30. Dale A, Strickland J, Symanzik J, Franzblau A, Evanoff B. Reliability of hand diagrams for the epidemiologic case definition of carpal tunnel syndrome. J Occup Rehabil. 2008 Sep;18(3):233-48. http://dx.doi.org/10.1007/s10926-0089139-y.

31. Bonauto DK, Silverstein BA, Fan ZJ, Smith CK, Wilcox DN. Evaluation of a symptom diagram for identifying carpal tunnel syndrome. Occup Med (Lond). 2008 Dec;58(8):561-6. http:// dx.doi.org/10.1093/occmed/kqn123. 
32. Armstrong T, Dale A, Franzblau A, Evanoff B. Risk factors for carpal tunnel syndrome and median neuropathy in a working population. J Occup Environ Med. 2008 Dec;50(12):1355-64. http://dx.doi.org/10.1097/JOM.0b013e3181845fb1.

33. Leffler CT, Gozani SN, Cros D. Median neuropathy at the wrist: diagnostic utility of clinical findings and an automated electro diagnostic device. J Occup Environ Med. 2000 Apr;42(4):398-409. http://dx.doi.org/10.1097/00043764200004000-00015.

34. Rempel D, Evanoff B, Amadio PC, de Krom M, Franklin G, Franzblau A, et al. Consensus criteria for the classification of carpal tunnel syndrome in epidemiologic studies. Am J Public Health. 1998 Oct;88(10):1447-51. http://dx.doi.org/10.2105/ AJPH.88.10.1447.

35. Letz R, Gerr F. Covariates of human peripheral nerve function: I. Nerve conduction velocity and amplitude. Neurotoxicol Teratol. 1994 Jan-Feb;16(1):95-104. http:// dx.doi.org/10.1016/0892-0362(94)90014-0.

36. Calfee RP, Dale AM, Ryan D, Descatha A, Franzblau A, Evanoff B. Performance of simplified scoring systems for hand diagrams in carpal tunnel syndrome screening. J Hand Surg Am. 2012 Jan;37(1):10-7. http://dx.doi.org/10.1016/j. jhsa.2011.08.016.

37. Descatha A, Dale AM, Franzblau A, Coomes J, Evanoff B. Comparison of research case definitions for carpal tunnel syndrome. Scand J Work Environ Health. 2011 Jul;37(4):298 306. http://dx.doi.org/10.5271/sjweh.3148.

38. Isolani L, Bonfiglioli R, Raffi GB, Violante F. Different case definitions to describe the prevalence of occupational carpal tunnel syndrome in meat industry workers. Int Arch Occup Environ Health. 2002;75:229-34. http://dx.doi.org/10.1007/ s00420-001-0304-2.

39. Kimura J. Electrodiagnosis in Diseases of Nerve and Muscle: Principles and Practice. Edition 3. Oxford University Press: Oxford, UK; 2001.

40. Werner RA, Franzblau A, Gell N, Hartigan AG, Ebersole M, Armstrong TJ. Incidence of carpal tunnel syndrome among automobile assembly workers and assessment of risk factors. J Occup Environ Med. 2005 Oct;47(10):1044-50. http://dx.doi. org/10.1097/01.jom.0000171065.17288.a0.

41. Bonfiglioli R, Mattioli S, Fiorentini C, Graziosi F, Curti S, Violante FS. Relationship between repetitive work and the prevalence of carpal tunnel syndrome in part-time and fulltime female supermarket cashiers: a quasi-experimental study. Int Arch Occup Environ Health. 2007 Jan;80(3):248-53. http://dx.doi.org/10.1007/s00420-006-0129-0.

42. Dekrom M, Knipschild PG, Kester ADM, Spaans F. Efficacy of provocative tests for diagnosis of carpal tunnel syndrome. Lancet. 1990 Feb 17;335(8686):393-5. http://dx.doi. org/10.1016/0140-6736(90)90218-T.

43. Homan MM, Franzblau A, Werner RA, Albers JW, Armstrong TJ, Bromberg MB. Agreement between symptom surveys, physical examination procedures and electro diagnostic findings for the carpel tunnel syndrome. Scand J Work Environ Health. 1999 Apr;25(2):115-24. http://dx.doi.org/10.5271/ sjweh.413.
44. Latko WA, Armstrong TJ, Franzblau A, Ulin SS, Werner RA, Albers JW. Cross-sectional study of the relationship between repetitive work and the prevalence of upper limb musculoskeletal disorders. Am J Ind Med. 1999 Aug;36(2):248-59. http://dx.doi.org/10.1002/(SICI)10970274(199908)36:2<248::AID-AJIM4>3.0.CO;2-Q.

45. Rosecrance JC, Cook TM, Anton DC, Merlino LA. Carpal tunnel syndrome among apprentice construction workers. Am J Ind Med. 2002 Aug;42(2):107-16. http://dx.doi. org/10.1002/ajim.10093.

46. Cartwright MS, Walker FO, Blocker JN, Schulz MR, Arcury TA, Grzywacz JG, Mora D, Chen H, Marin AJ, Quandt SA. The prevalence of carpal tunnel syndrome in Latino poultryprocessing workers and other Latino manual workers. J Occup Environ Med. 2012 Feb;54(2):198-201. http://dx.doi. org/10.1097/JOM.0b013e31823fdf53.

47. Patil A, Rosecrance J, Douphrate D, Gilkey D. Prevalence of carpal tunnel syndrome among dairy workers. Am J Ind Med. 2012 Feb;55(2):127-35. http://dx.doi.org/10.1002/ ajim. 21995 .

48. Gerr F, Marcus M, Ensor C, Kleinbaum D, Cohen S, Edwards A, et al. A prospective study of computer users: I. Study design and incidence of musculoskeletal symptoms and disorders. Am J Ind Med. 2002 Apr;41(4):221-35. http://dx.doi. org/10.1002/ajim.10066.

49. Bernard B. (Ed.) Musculoskeletal disorders and workplace factors: a critical review of epidemiologic evidence for workrelated musculoskeletal disorders of the neck, upper extremity, and low back. Cincinnati: Department of Health and Human Services NIOSH; 1997.

50. Abbas M, Afifi A, Zhang Z, Kraus J. Meta-analysis of published studies of work-related carpal tunnel syndrome Int J of Occup Environ Health 1998; 4:160-7.

51. Panel on Musculoskeletal Disorders and the Workplace, Commission on Behavioral and Social Sciences and Education, National Research Council and the Institute of Medicine. Musculoskeletal disorders and the workplace: low back and upper extremities. Washington, DC: National Academy Press; 2001.

52. Hegmann KT, Oostema SJ. Causal Associations and Determination of Work-Relatedness. Chapter 3. Melhorn JM, Ackerman WE (Eds). In: Guides to the Evaluation of Disease and Injury Causation. Chicago: American Medical Association Press; 2007.

53. Kong X, Gozani SN, Hayes MT, Weinberg DH. NC-stat sensory nerve conduction studies in the median and ulnar nerves of symptomatic patients. Clinical Neurophysiol. 2006 Feb;117(2):405-13. http://dx.doi.org/10.1016/j. clinph.2005.10.019.

Received for publication: 28 November 2012 